\title{
BMJ Open Examining positive views from students, trainees and GPs about general practice: a generational problem? A set of qualitative studies in France
}

Bernard Le Floc'h (D) , ${ }^{1,2}$ Hilde Bastiaens, ${ }^{3}$ Jean-Yves Le Reste, ${ }^{4}$ Patrice Nabbe, ${ }^{5}$ Tristan Montier, ${ }^{6}$ Lieve Peremans ${ }^{7}$

To cite: Le Floc'h B,

Bastiaens $\mathrm{H}$, Le Reste J-Y, et al. Examining positive views from students, trainees and GPs about general practice: a generational problem? A set of qualitative studies in France. BMJ Open 2022;12:e048857. doi:10.1136/ bmjopen-2021-048857

- Prepublication history and additional supplemental material for this paper are available online. To view these files, please visit the journal online (http://dx.doi.org/10.1136/ bmjopen-2021-048857).

Received 13 February 2021 Accepted 11 January 2022
Check for updates

(C) Author(s) (or their employer(s)) 2022. Re-use permitted under CC BY-NC. No commercial re-use. See rights and permissions. Published by BMJ.

For numbered affiliations see end of article.

Correspondence to Professor Bernard Le Floc'h; blefloch1@univ-brest.fr

\section{ABSTRACT}

Objective This study aimed to explore the positive factors related to working in general practice in France, from a student studying medicine, trainee general practitioner (GP) and GP point of view.

Setting Primary care, France.

Design Nine different qualitative studies involving medical students, trainees and GPs.

Participants Sixty-seven medical students, 22 trainees in general practice and $71 \mathrm{GPs}$.

Results The final codebook contained 66 interpretative codes and 8 positive themes. The themes were general practice as a commitment, doctor-patient care and relationships, skills and competencies in general practice, practice organisation and work-life balance, relationship with the professional community, GPs and university, GPs in the social community and private life, relatives and family. Positive feelings about being a GP are similar throughout the different age groups, from young students to older professionals.

Discussion and conclusion This study provided a comprehensive picture of the satisfied GP across different ages. This picture describes GPs as patient-centred professionals who need to have the freedom to choose an efficient working environment, organise their practice, have opportunities for professional development and acquire specific competencies. Both younger and older GPs believe in the future of general practice.

\section{INTRODUCTION}

Is there a generational conflict between general practitioners (GPs) and students or trainee practitioners? GPs have been heard claiming that younger doctors have no sense of vocation, whereas students and trainees voice concerns about working like their older colleagues.

The WHO emphasises the central role of general practice in European healthcare systems. ${ }^{1}$ However, GPs are an increasingly ageing population as fewer students are choosing general practice. ${ }^{2}$ Furthermore, the

\section{Strengths and limitations of this study}

- The study consists of nine homogeneous studies conducted throughout France as part of a broader European study; this allowed us to capture a rich data set.

- This study interviews a large, heterogenous mix of general practitioners (GPs), medical students and trainee GPs.

- The main weakness was a possible interpretation bias, but this bias was limited by the significant number of group meetings.

- This study was conducted in France, where trainees are considered to be students; however, the conclusions are the same in other countries with different study systems.

number of GPs is decreasing in France and in Europe as a whole. Compared with previous years, the current demographic profile in France highlights this problem of reducing GP numbers in practice and generational renewal. ${ }^{3}$

The reducing GP numbers have inspired many studies to investigate the reasons why GPs leave the profession. ${ }^{4}$ However, little research has focused on GPs who are satisfied in their clinical work. ${ }^{5}$ Yet, stressing the positive aspects of the profession might make general practice more attractive to students and physicians.

In previously published systematic reviews, our research team highlighted several positive satisfaction factors, intrinsic motivation and positive values associated with choosing to practice general medicine. ${ }^{67}$ To complete these literature reviews, the European General Practice Research Network research team conducted a series 
of qualitative studies in Europe. ${ }^{8}$ This article describes the French results.

This qualitative study aimed to explore the positive factors related to working in general practice in France, from the point of view of students, trainee GPs and practising GPs.

\section{METHODS}

To answer the research question, a descriptive, pragmatic, qualitative design was used for the nine different qualitative studies. These studies were conducted in France with medical students, trainee GPs and practising GPs in private clinics.

To gain insight into the different perspectives from these three populations, we collected data in various settings using semistructured interviews and focus groups. ${ }^{9}$

\section{Study setting and population}

For each study, students, trainees and GPs were selected using a purposive sampling strategy to obtain maximum population variation until data saturation was reached. The following criteria were used: gender, age and university for students and trainees, and gender, experience, age, type of practice (group or solo) and location (rural or urban) for GPs. GPs were selected randomly to ensure heterogeneity. Snowball sampling was used to recruit trainees and students.

\section{Five student and trainee studies}

The first study used semistructured interviews with trainees from different regions in France. These trainees had achieved excellent results in the undergraduate programme, which in the French points-based specialty selection system gave them access to a number of specialties, yet they chose general practice.

The second study used individual, semistructured interviews with students from different regions in France following their first training period in primary care. The objective was to explore their perception of general practice after this initial experience and before their definitive career choice.

In the third study, sixth-year undergraduate students were interviewed before choosing their specialty. Focus groups were chosen to facilitate the interaction between participants. ${ }^{10}$ Similarly, the fourth study interviewed sixth-year undergraduates; however, individual semistructured interviews were used to get a more intimate perspective.

In the fifth study, second-year medical students from west France were interviewed face-to-face to explore their views on general practice at the beginning of their educational programme.

\section{Four GP studies}

The first GP study was conducted in western France with face-to-face, individual, semistructured interviews to explore more personal, in-depth views of the profession.

\section{Box 1 Interview guide themes}

1. In your life as a general practitioner (GP)/during your general practice internship, you have probably had pleasant or amusing experiences. Could you tell us about one?

2. What do you like about being a GP/your future as a GP? What makes you happy to go to work every morning?

3. What is the ideal method for settling into practice successfully?

4. Which aspects of your job as a GP make it attractive for your family?

5. In what kind of environment do you like to live?

6. We discussed satisfaction at length. Is there anything we have not mentioned that makes you happy?

To triangulate these data, a second study was conducted with GP focus groups. The third study consisted of faceto-face interviews with young GPs (practising for less than 5 years) who had chosen to practice in a rural area to explore whether this younger population had different motives for choosing general practice.

The fourth study was conducted by phone with GPs throughout France to confirm results from the previous GP studies.

\section{Patient and public involvement}

This study had neither patient nor public involvement.

\section{Data collection}

All interviews were conducted between 2011 and 2016 . The interviewers were trained and used the same interview guide for all focus groups and semistructured interviews. The interviewers also used the same topic list for focus groups and semistructured interviews (Box 1). The interview guide, composed of six open questions, was slightly adapted for each target population.

The research group created the guide which was then tested in France. It was slightly revised after the first study so participants could understand it more easily. Focus groups and individual interviews were audio-taped and video-taped and verbatim was transcribed. Data were collected until data saturation was achieved. Saturation was achieved when all items and topics were covered, and no new codes emerged from the verbatim. Final interviews were conducted to ensure saturation and no new information emerged.

\section{Data analysis}

The verbatim was analysed thematically. The first step consisted of data familiarisation, where different researchers read the transcripts several times and made notes. In the second step, descriptive codes were formulated, followed by interpretative coding.

For each study, two researchers coded the transcripts independently and compared their analysis results at the end of every coding step. The codes from the first interviews were synthesised in a codebook, which evolved to include the codes, a brief definition of the codes and notes. The codebook was used to code subsequent interviews and new codes were added. 
In the final stage, the codes were reorganised into themes and subthemes. ${ }^{11}$

A group of senior researchers supervised all coding and organisation between themes and subthemes (J-YLR and $\mathrm{BLF}$ ). If discrepancies occurred, the whole group tried to obtain a consensus. The whole research team validated the final themes.

\section{Quality control}

The sampling strategy aimed to include GPs, trainees and students with maximal heterogeneity. Researcher and data triangulation strengthened credibility. In the second stage, all researchers collaborated to review each coding step and agreed on the final theme list. Two experienced researchers (LP and $\mathrm{HB}$ ) performed an external data audit.

\section{RESULTS}

Overall, 160 respondents were included in the nine studies.

\section{Student and trainee studies}

Three studies included a total of 67 students and two studies included 22 trainees. The maximum variation principle was applied to all these studies, focusing on location (rural or urban), gender and socio-occupational category of the parents.

\section{GP studies}

The research group conducted four studies including 33 individual interviews and 5 focus groups with 38 GPs. As was expected for this time-pressed population, those who declined gave reasons including prior engagements and heavy workload rather than lack of interest in the study. Saturation with axial coding was reached for each study.

Table 1 summarises the study design.

\section{Data analysis}

An overview of the in-depth analysis of each subgroup was given. All descriptive codes have been aggregated into 66 interpretative codes which were found in the student, trainee and GP populations. Except for some nuances, the main themes were the same for students, trainees and GPs (table 2). Trainees and students had very similar views as neither group is practising as GPs.

\section{General practice as a commitment}

The intrinsic characteristics of the GP as a person were important for all respondents. Even young students stated that general practice was a commitment to providing holistic patient care and not just treating illness. They wanted to become GPs to help people, relieve their suffering and treat or improve their conditions or illnesses. GPs were motivated to take care of people and meet their needs. They also identified trainees who had intrinsic personality traits suited to becoming an efficient GP.

It's important to look at the patient as a whole and not just focus on one area or organ. (Trainee)

People who will be able to trust me, who can tell me their problems, and trust me to help. (Trainee)

Table 1 Participants, setting and design of the different studies

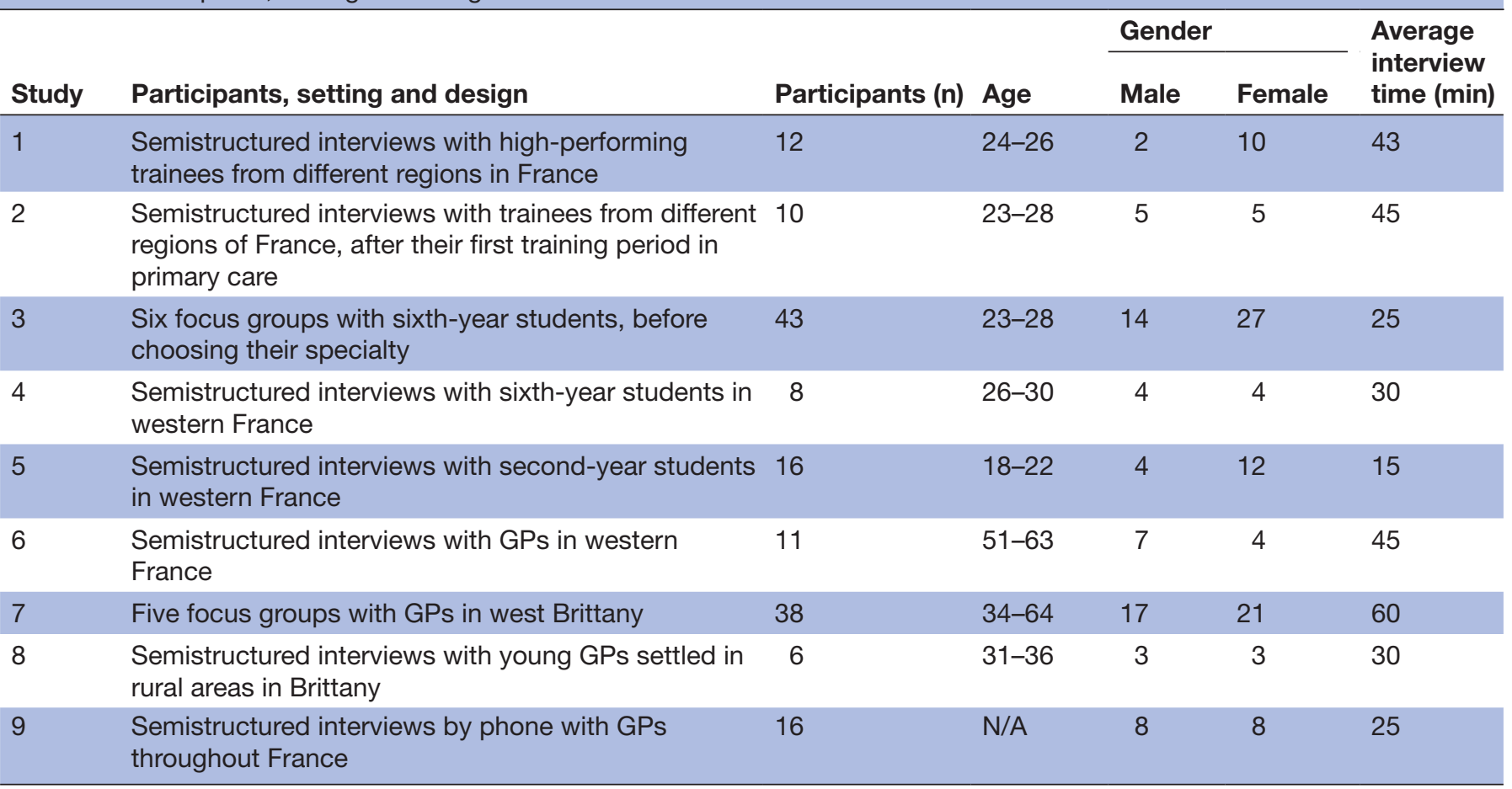

GP, general practitioner. 
Table 2 Themes, comparison between students and trainees, and GPs

\begin{tabular}{|c|c|c|}
\hline Themes & Students and trainees & GPs \\
\hline $\begin{array}{l}\text { General practice as a } \\
\text { commitment }\end{array}$ & $\begin{array}{l}\text { Commitment to become a GP and to } \\
\text { help people }\end{array}$ & $\begin{array}{l}\text { Commitment to general practice to take care of } \\
\text { patients }\end{array}$ \\
\hline $\begin{array}{l}\text { General practice, skills and } \\
\text { competencies }\end{array}$ & $\begin{array}{l}\text { Encounter a wide variety of diseases } \\
\text { and conditions, intellectual stimulation, } \\
\text { challenging discipline }\end{array}$ & $\begin{array}{l}\text { Challenging and satisfying profession (technical } \\
\text { skills), acquisition of new skills, intellectual } \\
\text { stimulation }\end{array}$ \\
\hline $\begin{array}{l}\text { Practice organisation and work- } \\
\text { life balance }\end{array}$ & $\begin{array}{l}\text { Good work-life balance, lower income } \\
\text { but lower workload, multidisciplinary } \\
\text { practice }\end{array}$ & $\begin{array}{l}\text { Good work-life balance with a satisfying income, } \\
\text { independence and freedom in workplace } \\
\text { organisation }\end{array}$ \\
\hline $\begin{array}{l}\text { Relationship with the professional } \\
\text { community }\end{array}$ & $\begin{array}{l}\text { Pleasant and skilled colleagues, support } \\
\text { in patient care, collaboration with } \\
\text { specialists or paramedics }\end{array}$ & $\begin{array}{l}\text { Harmonious professional relationships, work with } \\
\text { satisfied colleagues with a positive attitude }\end{array}$ \\
\hline GP status in the social community & $\begin{array}{l}\text { Practice location determined by where } \\
\text { they came from, job opportunities } \\
\text { and affinities with certain practices or } \\
\text { locations, profession of spouse and } \\
\text { amenities for family life }\end{array}$ & $\begin{array}{l}\text { Family and GP satisfied with relationships within } \\
\text { the community }\end{array}$ \\
\hline Private life, relatives and family & $\begin{array}{l}\text { Having free time (hobbies and leisure), } \\
\text { amenities for family (jobs, schools and } \\
\text { neighbourhood) }\end{array}$ & $\begin{array}{l}\text { Manage professional and private life, complete } \\
\text { family life }\end{array}$ \\
\hline
\end{tabular}

A complete description of the data is described in online supplemental appendix 1 .

GP, general practitioner.

If he has a personality suited to General Practice, he will succeed. (GP)

You should also have self-respect and that is very complicated at first. (GP)

GPs consciously spoke about the need to take care of themselves by maintaining physical and mental health and the importance of remaining ordinary people, integrated into their community. In contrast, students did not talk about taking care of themselves literally but did discuss the need for an acceptable work-life balance.

In hospital, we have an illness-focused approach and try to correct the illness, there is less interest in what is around. I find it extremely interesting that there is the patient with their health problems but also their whole environment which determines the care they will receive. I find that is a more comprehensive perception of the individual than the hospital approach. (GP)

Being physically and mentally healthy. (GP)

Having a normal life. (Student)

Students are aware of the need for flexibility and are not anxious about coping with unpredictable situations; they even find them challenging. During their career, GPs develop strong coping strategies to handle unpredictable situations, a broad range of diseases, and different types of patients and contexts. They know their professional limitations and the need to control the level of patient involvement. GPs have the skills to be empathetic without being overwhelmed.

When we start in the morning, we do not know what we will see during the day. This is an advantage. We have no idea what we will find when we open the door, we do not know what the problem will be. (Student)

It's a job where we always question our practices and we learn, there's plenty to do, it's very interesting, it's very vast. (Student)

Having to deal with difficult situations, such as giving someone bad news. (GP)

\section{Doctor-patient care and relationships}

GPs felt it was important that patients can choose their doctor as both parties need to feel comfortable due to the long-term personal relationship between GPs and patients. They also stated that this relationship was enriched over time since GPs grow older alongside their patients. 
French GPs come from a long tradition of taking care of their own patients. These patients are used to being treated by a single GP and expect to build a lifelong, trustbased relationship . Even young students saw the importance of the unique doctor-patient relationship.

The patient's history.... (GP)

The special relationship..., it's great to know the patients, to ask "how's your mother?". Ultimately, they really know everything about the patient.... (Student)

To have real contact, a durable link with the patients ... I would really like to have continuous follow-up and a connection with them. (Second year student)

Students and trainees appreciated this long-term relationship but, as their careers advanced, GPs also became more involved with other family members, whole families or several generations. This special relationship is a source of satisfaction. GPs liked the respect, and they appreciated the gratitude they received.

To be able to follow four generations of a family is quite rewarding for a GP. It's been a while since I set up in practice, so to follow entire families is great! (GP)

We follow them up; we will see whole families, with different generations. (Trainee)

There was a mutual trust between GPs and patients. Negotiating with patients about managing their condition can be difficult but GPs were happy when they came to an agreement.

Communicating with patients and feeling competent in solving their problems were the greatest sources of satisfaction.

With some people you have to speak, with other people you have to listen. (GP)

They wished to provide comprehensive and holistic care, looking at the patient as a whole, not just their medical condition. They highlighted the importance of good communication and understanding the patient's perspective, their personal view, especially when dealing with care management and ethical questions.

I let the patient choose because of their own personal or family history. (GP)

\section{General practice, skills and competencies}

Both GPs and students described general practice as an interesting profession.

I always enjoy going to work. (GP)

When I went to work with the GP, I was happy to go. (Trainee)

They also described the GP role as the first point of access to care having a wide range of varied activities and different health problems to solve. Students talked with respect about the GP performance during their work experience in practice. They described their role as being more challenging than just seeing people, talking to them and writing repeat prescriptions. Even second-year students mentioned the diversity of activities. This diversity seems to become apparent during their education; medical students came to realise that they preferred to take a holistic approach rather than focus on one organ.

It's ideal. Consultations are diverse with two types of patient: those that I follow-up regularly, and those who have just arrived, whom I will get to know. A GP's work is diverse and includes all age-groups. I see fairly common diseases and some that are more difficult to identify and analyze. (Second-year student)

I think it's where we see the most varied things compared with a specialty, for example in cardiology, we focus on the heart... Patients are followed-up longterm so we ... create a relationship with them. In the hospital, ... often ... we see them for a week and, ... never see them again or see them again three years later. Here, we really have time to create a relationship and we see that we are important to them. (Student)

There is no routine because you never know what will happen the next day. (GP)

We do not know what to expect in each consultation. (Student)

We identified that GPs need specific competences. They use clinical reasoning for diagnostic procedures and evidence-based practice to make therapeutic decisions. They also have to be trained in different technical and communication skills. Students were impressed by the GPs' scientific and technical skill levels.

The attraction I see in general practice is that it's never finished. "We have never dealt with the problem all at once, we did not respond with "that's it". It's never finished and you have to consider everything the physical, psychological and social aspects". (Trainee). I realized this semester, that guidelines are indispensable. You have to have guidelines, and they really help decision making. It's really useful. Furthermore, you're not alone. You work with everyone else. (Trainee)

GPs also enjoy having additional occupations that provide extra challenges above daily general practice such as teaching, or having medical responsibilities in a nursing home or sporting organisation.

There are quite a few who work in general practice but also do sessions at the hospital or in a sports facility. It's something that I very much like: diversifying. (Trainee)

Practice organisation, work-life balance and relationships with the professional community

French GPs wanted to have freedom to choose their workplace organisation. They found satisfaction in being 
their own boss and in choosing their own colleagues and practice equipment. Working with a competent practice support team, including secretaries and nurses, with good technical resources is the ingredient for a wellfunctioning practice. Students wanted to work in multidisciplinary groups.

... within a building that would allow interaction between different doctors and health professionals, also paramedical personnel. I especially value the interaction and not finding myself alone in my practice and only seeing patients all day long. (Student)

I think it would be good to work in a practice where there can be doctors, receptionists and even physiotherapists, for example? It allows us to discuss patients, have a better follow-up, personalize things, and even to learn physiotherapy because we do not necessarily know all the methods. I know that system exists near me, and I find it really good .... (Student)

Having other people who can help in case of problems is reassuring. (Student)

Doctors and students stressed the importance of organised continuity of care.

Mobile phones arrived liberating us! (GP)

I am not a big fan of out-of-hours working. (Student)

I do not want crazy schedules. (Student)

GPs and students liked to be at the centre of care and the link between other specialties. They wanted efficient support from other specialties and paramedics.

Good collaboration between different health professionals. (Student)

\section{GPs and university}

GPs were proud that general practice was more accessible during medical studies. The general practice rotation provided an important opportunity for the students to experience the specialty. Some GPs were teachers in general practice, or tutors, and wanted to undertake research in general practice. Having effective working relationships between GPs, students and trainees was a positive factor which made the profession more attractive. Trainees and GPs learnt from each other, changing the work perspective.

It's also a pleasure to work with someone who is there to ask question. (Student)

And be able to do research. (Student)

My involvement with trainees is an ongoing pleasure! (GP)

I was already thinking about it, so I decided that I was going to do a general medicine rotation and this confirmed my choice. I think we should work with practitioners because I find that people do not necessarily have a good idea of what is done and a clear picture of what it is like. (Student)
GP status in the social community and private life, relatives and family

Some GPs felt that being able to choose their practice location was desirable.

My parents and sister are not too far away. (Second-year student)

They chose from the opportunities presented according to their own background. Trainees did not want to work in isolated regions without facilities or support.

I'm still young and I cannot imagine myself in the countryside, I don't want to be too lonely and isolated. (Student)

GPs felt the social community was important and wanted to be part of the community where they lived but felt it was important to be able to choose their level of involvement. They needed active social contacts and a broader vision of the patients outside the limits of the practice. GPs found it satisfying that general medicine is a respected profession.

You must also gain respect and that is very complicated at first. (GP)

Income was also important.

I admit that it is a comfort, extraordinary, not to have any money worries! (GP)

I'm sure I'll make a good living. (Student)

GPs looked for amenities for their family, such as schools and leisure facilities for their children, and employment for their spouse. They wanted to have a complete family life, the opportunity to have holidays, with enough money and time to enjoy it.

To manage professional and private life, it is useful to apply limits to the demands of the profession. GPs wanted family and social support in their profession.

My family is proud of me...seeing me as a GP(Student).

The family (parents, spouse, children) was considered when making professional choices.

\section{DISCUSSION}

Our results highlight positive visions of being a GP, of which most are expressed throughout the different age groups, from young students to older professionals. The most important positive factors were the long-term and solid doctor-patient relationship, the intellectual aspects, professional diversity and the opportunities to work in a multidisciplinary practice with pleasant colleagues. Interestingly, students in undergraduate education have the same point of view as their older colleagues, and having positive experiences during their training strengthens these opinions. In fact, during the early years of medical education, both students and trainees had already begun to consider general practice as a specialty. 
These results confer with other qualitative and quantitative studies, which highlight factors relating to GP job satisfaction. Laurence et al found young GPs in rural areas of South Australia had a sense of community, wanted positive relationships with patients and recognition of their family's needs. ${ }^{12}$ Although the notion of rurality differs between France and Australia, our results are quite similar. Australian GPs also want to work in a well-organised practice with a friendly atmosphere and support from senior GPs. Additionally, a New Zealand qualitative study highlighted the importance of the environment and status in the community for the rural GPs and their families. ${ }^{13}$ Walker and Pirotta ${ }^{14}$ found that in Australia, factors such as being female, older, having a healthy lifestyle and a lower body mass index were positively associated with job satisfaction. In another Australian study, McGrail et $a l^{15}$ found that professional satisfaction correlated with free choice of work method, variety of work, good working conditions, opportunities to use skills or specific competencies, level of responsibility and good relationships with colleagues. Similarly in Germany, Goetz et $a l^{16}$ found that GPs were satisfied with their job with the exception of 'hours of work', 'physical working conditions', and 'income'. In these studies, there is no mention of factors such as doctor-patient relationship, the opportunities to teach and train and the doctor as a person.

Furthermore, Roos et al surveyed trainees and young GPs in different European countries to understand their motivational factors. They found compatibility with family life $(59.5 \%)$, working in a challenging discipline $(58.9 \%)$, an individual approach to people $(40.1 \%)$ and a holistic approach towards the patient $(37.8 \%),{ }^{17}$ which are consistent with the results of the present study.

Satisfied GPs tend to stay in practice working when it is well organised, set in a pleasant environment with diverse opportunities to use their technical skills, where traineeship is provided and where they have time for personal development. This was also found in other studies. ${ }^{18} 19$ Additionally, our results describe the GP as a person with strong coping strategies willing to maintain a holistic approach towards patient care and work with uncertainties to make correct diagnoses and referrals.

Interpersonal relationships were important at every stage of the doctor's career. GPs wanted personal relationships with their colleagues. Young people wanted to work with older GPs and specialists and have technical support. We found students appreciated working in multidisciplinary settings, in which other healthcare providers can help with problems, following guidelines, and a having a good work-life balance with family support.

Numerous studies have demonstrated the value of primary care training in attracting young doctors to general practice. ${ }^{20-23}$ A Canadian qualitative study, using the Delphi method, ${ }^{24}$ found that teaching, sharing knowledge and experience, and mentoring are some rewards of family practice. Data collected from students at different stages show that their perception changes during their course. The popularity of general practice as a career option increases significantly over the course of their medical studies. ${ }^{23}$ Although most young students are initially unclear about their future career path, they share some points of view about general practice with older students or GPs. Comparisons between the results of our studies with participants of different ages and genders made it possible to describe a particular GP personality or portrait of a GP as a person, which is common among all generations. Young students have an ideal vision of general practice centred around helping people, while the older students have a more pragmatic, patientcentred, vision.

Our study found that some intrapersonal determinants seem more important. Gill et al, in a Canadian study, found that medical students who preferred general practice as a career choice appeared to be influenced by a different set of factors from those who preferred other specialties. These included being female, being older, having previously lived in a rural location, placing importance on continuity of care, desiring a shorter residency, the influence of family, friends or community, and the opportunity to deal with a variety of medical problems. ${ }^{25}$ The job satisfaction of future GPs is determined by some specificities described under the theme 'GP as a person' and 'patient care and relationships'. Current selection of medical students in France does not sufficiently consider these specificities.

This study might have some implications for the medical student selection process. Currently, most students selected felt most comfortable operating in a positivist paradigm being highly interested in science and being less competent for general practice, psychiatry and geriatrics. During recruitment and training, it is important to look beyond academic and clinical competency towards personal attributes. These attributes, including empathy, sensitivity, communication skills, clinical knowledge and coping with pressure, all need to be considered..$^{26}$

It is necessary to support students who might be interested in general practice to encourage them from the start of the curriculum and offer a longitudinal programme with the skills and competencies needed for general practice, as Pfarrwaller et al found in a systematic review on interventions. ${ }^{27}$ General practice rotations are important and gave students a positive view. There is some conflicting evidence that in the case of prestigious training placements, rotations might have a greater influence for general practice than for other disciplines. However, rotations are not the only route to solving the problem of lack of interest and probably occur too late in medical training to be a solution.

Training courses which consider qualitative factors tailored to general practice are important. They allow young doctors to find out about the profession and can reinforce their motivation to choose primary care. Universities and professional organisations need to be more creative and organise continuous professional development courses in more rural areas closer to practices. 
Furthermore, local policymakers could find functional locations to facilitate new practices being set up.

\section{Strengths and limitations}

This study was the first qualitative study in France involving students, trainees and GPs to provide an in-depth view of the factors which make general practice attractive and provide enduring satisfaction within that profession..$^{56}$ The main strength of this study is that it is composed of a set of nine homogeneous studies which were conducted throughout France with a French collaborative team, in conjunction with a European team.

One limitation is that some interviewees were young students and that as a result, the data might not have been so rich. Some long-distance interviews were conducted by telephone and not face-to-face. However, saturation was reached in every study.

\section{CONCLUSION}

This study provides a portrait of a satisfied GP and shows common ground from the beginning of training to retirement. Satisfied GPs are technically skilled and highly effective communicators with efficient coping strategies equipping them to manage patients with a wide variety of diseases. Students and GPs are attracted by the holistic approach and the unique long-term doctor-patient relationship. Freedom, conviviality and intellectual stimulation are positive factors which enhance the attractiveness of general practice and encourage GPs to remain in practice.

To improve family physician demographics, public authorities need to take personal attributes into account and consider introducing the attractiveness and satisfaction factors found in our study into the student selection process and during medical studies. Student selection needs to focus on training in the doctor-patient relationship, the patient-centred approach and the desire of future doctors to be involved in helping patients. It is essential that lecturers in general practice nurture these characteristics during medical training.

\section{Author affiliations}

${ }^{1}$ Department of General Practice, Université de Bretagne Occidentale, Brest, France ${ }^{2}$ EA 7479 SPURBO, Université de Bretagne Occidentale, Brest, France

${ }^{3}$ Department of Primary and Interdisciplinary Care, Faculty of Medicine and Health Sciences, University of Antwerp, Wilrijk, Belgium

${ }^{4}$ Médecine Générale, Université de Bretagne Occidentale, Brest, France ${ }^{5}$ Médecine Générale EA Spurbo, Université de Bretagne Occidentale, Brest, France ${ }^{6}$ Unité INSERM 1078, SFR 148 ScInBioS, Université Européenne de Bretagne, Faculté de Médecine et des Sciences de la Santé, Université de Bretagne Occidentale, Brest, France

${ }^{7}$ Primary Care, Faculty of Medicine and Health Sciences, University of Antwerp, Wilrijk, Belgium

Acknowledgements We sincerely thank the European General Practice Research Network for its support in the survey. Also, we thank all the European Womanpower study staff involved: Lingner H, Hoffman R, Czachowski S, Assenova R, Koskela T, Klemenc-Ketis Z and Sowinska A. The authors warmly thank all the students, trainees and general practitioners who kindly gave their time to take part in this study. The authors acknowledge Charlotte Wright and Amanda Whereat of Speak the Speech Consulting for editing the manuscript. The authors are grateful for the comments and suggestions provided by Alex Gilman and the work of C Bossard, $\mathrm{F}$ Bovay, J Bry, G De Chazal, J-P Hefner, S L'Echelard, P Le Grand, P Le Floch, M Cam and K Stolc.

Contributors BLF and J-YLR designed the study, collected data, and drafted and revised the paper. HB designed the study, collected data and revised the paper. PN revised the paper. TM revised the paper. LP designed the study revised the paper. $\mathrm{BLF}$ is responsible for the overall content as the guarantor.

Funding This project had an European General Practice Research Network funding of $€ 8000$.

Competing interests None declared.

Patient consent for publication Not applicable.

Ethics approval This study involves human participants and was approved by the ethical committee of the Université de Bretagne 0ccidentale, France, approved the study for the whole of Europe: Decision $N^{\circ} 6 / 5$ of 5 December 2011. Participants gave informed consent to participate in the study before taking part.

Provenance and peer review Not commissioned; externally peer reviewed.

Data availability statement Data are available upon reasonable request. All data and materials would be sent on request at Département Universitaire de Médecine Générale, Faculté des Sciences de la Santé, 22 av Camille Desmoulins, 29200 Brest Cedex, France.

Supplemental material This content has been supplied by the author(s). It has not been vetted by BMJ Publishing Group Limited (BMJ) and may not have been peer-reviewed. Any opinions or recommendations discussed are solely those of the author(s) and are not endorsed by BMJ. BMJ disclaims all liability and responsibility arising from any reliance placed on the content. Where the content includes any translated material, BMJ does not warrant the accuracy and reliability of the translations (including but not limited to local regulations, clinical guidelines, terminology, drug names and drug dosages), and is not responsible for any error and/or omissions arising from translation and adaptation or otherwise.

Open access This is an open access article distributed in accordance with the Creative Commons Attribution Non Commercial (CC BY-NC 4.0) license, which permits others to distribute, remix, adapt, build upon this work non-commercially, and license their derivative works on different terms, provided the original work is properly cited, appropriate credit is given, any changes made indicated, and the use is non-commercial. See: http://creativecommons.org/licenses/by-nc/4.0/.

ORCID iD

Bernard Le Floc'h http://orcid.org/0000-0003-2405-6634

\section{REFERENCES}

1 Evans T, Van Lerberghe W. The World Health Report 2008: Primary Health Care : Now More Than Ever. Geneva: World Health Organization, 2008.

2 Lefevre JH, Roupret M, Kerneis S, et al. Career choices of medical students: a national survey of 1780 students. Med Educ 2010;44:603-12.

3 Mourges J-M, Le Breton-Lerouvillois G. Atlas 2017 de la Démographie Médicale. Paris, 2017. Available: https://www.conseilnational.medecin.fr/sites/default/files/cnom_demographie2017.pdf

4 Hann M, Reeves D, Sibbald B. Relationships between job satisfaction, intentions to leave family practice and actually leaving among family physicians in England. Eur J Public Health 2011;21:499-503.

5 Van Ham I, Verhoeven AAH, Groenier KH, et al. Job satisfaction among general practitioners: a systematic literature review. Eur J Gen Pract 2006;12:174-80.

6 Le Floch B, Bastiaens H, Le Reste JY, et al. Which positive factors determine the GP satisfaction in clinical practice? A systematic literature review. BMC Fam Pract 2016;17:133.

7 Le Floch B, Bastiaens H, Le Reste J, et al. Which positive view of general practice do medical students and trainees have? A systematic literature review. Educ Prim Care 2020;31:104-11.

8 Le Floch B, Bastiaens H, Le Reste JY, et al. Which positive factors give general practitioners job satisfaction and make general practice a rewarding career? a European multicentric qualitative research by the European general practice research network. BMC Fam Pract 2019;20:96.

9 Sandelowski M, Voils Cl, Leeman J, et al. Mapping the mixed Methods-Mixed research synthesis terrain. J Mix Methods Res 2012;6:317-31. 
10 Kitzinger J. Qualitative research. Introducing focus groups. BMJ 1995;311:299-302.

11 Pope C, Ziebland S, Mays N. Qualitative research in health care. Analysing qualitative data. BMJ 2000;320:114-6.

12 Laurence CO, Williamson V, Sumner KE, et al. "Latte rural": the tangible and intangible factors important in the choice of a rural practice by recent GP graduates. Rural Remote Health 2010;10:1316.

13 Noonan T, Arroll B, Thomas D, et al. When should I do rural general practice? A qualitative study of job/life satisfaction of male rural GPs of differing ages in New Zealand. N Z Med J 2008;121:59-67.

14 Walker KA, Pirotta M. What keeps Melbourne GPs satisfied in their jobs? Aust Fam Physician 2007;36:877-80.

15 McGrail MR, Humphreys JS, Scott A, et al. Professional satisfaction in general practice: does it vary by size of community? Med J Aust 2010;193:94-8.

16 Goetz K, Musselmann B, Szecsenyi J, et al. The influence of workload and health behavior on job satisfaction of general practitioners. Fam Med 2013;45:95-101.

17 Roos M, Watson J, Wensing M, et al. Motivation for career choice and job satisfaction of GP trainees and newly qualified GPs across Europe: a seven countries cross-sectional survey. Educ Prim Care 2014;25:202-10.

18 Geneau R, Lehoux P, Pineault R, et al. Primary care practice a la carte among GPs: using organizational diversity to increase job satisfaction. Fam Pract 2007;24:138-44.
19 Backer EL, Mcllvain HE, Paulman PM, et al. The characteristics of successful family physicians in rural Nebraska: a qualitative study of physician interviews. J Rural Health 2006;22:189-91.

20 Parker JE, Hudson B, Wilkinson TJ. Influences on final year medical students' attitudes to general practice as a career. $J$ Prim Health Care 2014;6:56-63.

21 Bunker J, Shadbolt N. Choosing general practice as a career - the influences of education and training. Aust Fam Physician 2009;38:341-4.

22 Russell DJ, McGrail MR, Humphreys JS, et al. What factors contribute most to the retention of general practitioners in rural and remote areas? Aust J Prim Health 2012;18:289-94.

23 Hogg R, Spriggs B, Cook V. Do medical students want a career in general practice? A rich mix of influences!. Education for Primary Care 2008;19:54-64.

24 Manca DP, Varnhagen S, Brett-MacLean P, et al. Rewards and challenges of family practice: web-based survey using the Delph method. Can Fam Physician 2007:53:278-86.

25 Gill H, McLeod S, Duerksen K, et al. Factors influencing medical students' choice of family medicine: effects of rural versus urban background. Can Fam Physician 2012;58:e649-57.

26 Patterson F, Ferguson E, Lane P, et al. A competency model for general practice: implications for selection, training, and development. Br J Gen Pract 2000;50:188-93.

27 Pfarrwaller E, Sommer J, Chung C, et al. Impact of interventions to increase the proportion of medical students choosing a primary care career: a systematic review. J Gen Intern Med 2015;30:1349-58. 